\title{
Influence of Framing and Graphic Format on Comprehension of Risk Information among American Indian Tribal College Students
}

\author{
Debra Sprague, $\mathrm{PhD}^{1,2}$, Joan E. Russo, $\mathrm{PhD}^{3}$, Donna L. LaVallie, DO, MPH ${ }^{1,4}$, and Dedra S. \\ Buchwald, MD ${ }^{1,2}$ \\ ${ }_{1}^{1}$ Partnerships for Native Health, University of Washington, Box 359780, Seattle, WA USA \\ ${ }^{2}$ General Internal Medicine, University of Washington, Box 359780, Seattle, WA USA \\ ${ }^{3}$ Department of Psychiatry and Behavioral Sciences, University of Washington, Seattle, WA USA \\ ${ }^{4}$ Medical Education and Biomedical Informatics, University of Washington, Seattle, WA USA
}

\section{Abstract}

We evaluated methods for presenting risk information by administering 6 versions of an anonymous survey to 489 American Indian tribal college students. All surveys presented identical numeric information, but framing varied. Half expressed prevention benefits as relative risk reduction, half as absolute risk reduction. One-third of surveys used text to describe prevention benefits; $1 / 3$ used text plus bar graph; $1 / 3$ used text plus modified bar graph incorporating a culturally tailored image. The odds ratio (OR) for correct risk interpretation for absolute risk framing vs. relative risk framing was $1.40(95 \% \mathrm{CI}=1.01,1.93)$. The $\mathrm{OR}$ for correct interpretation of text plus bar graph vs. text only was $2.16(95 \% \mathrm{CI}=1.46,3.19)$; OR for text plus culturally tailored bar graph vs. text only was $1.72(95 \% \mathrm{CI}=1.14,2.60)$. Risk information including a bar graph was better understood than text-only information; a culturally tailored graph was no more effective than a standard graph.

\section{Keywords}

risk information; health communication; American Indian/Alaska Native; American Indian students; tribal college

\section{Introduction}

Effective risk communication is a crucial component of shared decision-making among health care providers and patients $[1,2]$. Understanding risk requires the comprehension of numeric information, which is difficult for many Americans. National surveys have found that almost half of U.S. adults do not understand numbers presented in text [3]. Similarly, according to a review of 85 studies including over 30,000 participants, almost half have low or marginal levels of health literacy [4]. Framing, which we define as the presentation of equivalent information in different ways, may also affect understanding (5-10]. Some studies have found that participants were better able to understand risk information framed in terms of relative risk (percentage) compared to absolute risk (frequency) [10,11], but it is difficult to compare findings because of a lack of consistency in risk communication testing

Address correspondence and reprint requests to Debra Sprague, General Internal Medicine, University of Washington, Box 359780, Seattle, WA 98195. Telephone: 206-543-2260, FAX: 206-543-3830; dsprague@u.washington.edu. 
format [12]. Finally, considerable research has shown that presenting numerical information in visual form rather than simply as text will increase comprehension $(11,13-15]$ and influence decision making $[16,17]$.

In 2 recent studies, we examined the comprehension of numerical risk information and the influence of framing and visual content among American Indians/Alaska Natives (AI/ANs), a population which has not been included in previous risk information research. In a survey of 300 American Indian employees (mean age 44 years) on a western American Indian reservation, we found that use of a graphic image (an icon array) increased understanding of risk interpretation but that framing information as relative compared to absolute risk was not significantly associated with risk interpretation. However, we did observe a slight trend toward relative risk being associated with more correct answers [18]. In another study of 91 $\mathrm{AI} / \mathrm{AN}$ elders (mean age 64) measuring numeracy skills and the correlation between framing of risk and risk understanding, we found that framing in terms of relative risk was associated with higher odds of correct interpretation compared to absolute risk and number needed to treat [19]. We were interested in investigating understanding of relative risk vs. absolute risk and the relationship between risk comprehension and graphic display with a younger college $\mathrm{AI} / \mathrm{AN}$ population. Additionally, we wished to investigate findings from focus groups of AI/ ANs who told us that they preferred culturally tailored images. We hypothesized that preference might increase engagement and thus understanding might be improved by including culturally tailored graphs.

Therefore, the goal of the present investigation was to evaluate 2 methods for presenting risk information to AI/AN students attending tribal colleges. Using a $2 \times 3$ factorial, randomized design, we asked 1) Does framing information in terms of relative or absolute risk influence comprehension of the benefits of 2 hypothetical cancer prevention plans? 2) Does the inclusion of a bar graph enhance the interpretation of risk reduction, compared to text-only content? and 3) Does a modified bar graph incorporating a culturally tailored image enhance interpretation, compared to a standard bar graph?

\section{Methods}

\section{Participants and recruitment}

Potential study participants were students aged 18 years and older enrolled at 3 tribal colleges located west of the Mississippi River. Although the student populations at all 3 colleges were predominantly but not exclusively AI/AN, surveys were offered to all students. The present analysis is confined to students who responded "Yes" to the question, "Are you of American Indian or Alaska Native heritage?" Survey planning and administration were conducted in collaboration with on-site coordinators and student research assistants. Recruitment took place during one week of each academic quarter in January 2008, March 2008, October 2008, and February 2010 at one campus; in June and September 2009 at the second campus; and in November 2009 at the third campus. At each college, flyers were posted the week preceding the survey dates, and tables were set up in locations predicted to have the most student traffic.

Students who approached the recruiting table were informed that the study was about health risk information and cancer prevention, then asked to complete the anonymous survey independently at nearby tables. Surveys were distributed in computer-generated random order. Participants received a $12.5 \mathrm{MB}$ jump drive after returning the survey. All study procedures were approved by the Institutional Review Board at each tribal college and at the University of Washington, where the researchers were based. 


\section{Survey}

We developed the survey in 6 different versions, allowing us to compare various aspects of risk communication. All 6 versions began with a vignette and 3 related questions; both the vignette and the questions were adapted from previous work [10]. The vignette presented baseline risk information about a hypothetical type of cancer and the possible benefits of 2 hypothetical prevention plans, Prevention Plan R and Prevention Plan K. Respondents were asked to imagine that 30 out of 100 people would develop cancer over their lifetime. In the relative risk versions, the vignette stated that Prevention Plan $\mathrm{R}$ reduced the risk of developing cancer by $33 \%$ and Prevention Plan K reduced the risk by $17 \%$. In the absolute risk versions, Prevention Plan R reduced the risk of developing cancer by 10 per 100 persons, and Prevention Plan K reduced the risk by 5 per 100 persons. We adapted the vignette on the basis of our findings from focus group reviews of various vignettes for cultural relevance and understandability, including focus groups with AI/ANs conducted before the present study [20,21], as well as focus groups conducted on 2 separate occasions with students at one of the tribal colleges. During the first meeting of the tribal college focus group, students provided general feedback on the survey and on culturally appropriate images created by AI/AN artists. The modified bar graph for Tribal College A incorporated a traditional design that would be familiar to its students, while the modified graph for Tribal Colleges B and C incorporated a bison motif (Figure 1). The survey was revised on the basis of initial focus group recommendations and reviewed at the second meeting.

The 6 resulting versions of the survey allowed us to compare framing (relative risk expressed as a percentage vs. absolute risk expressed as a frequency) and format (text only, text plus a standard bar graph, and text plus a culturally tailored bar graph). This 2 × 3 factorial design evaluated the 6 possible combinations of framing and format. Numeric information was identical in all 6 versions of the surveys; 3 versions framed the prevention benefits in terms of relative risk reduction and 3 in terms of absolute risk reduction. All surveys used identical text to describe the benefits of the prevention plans. Two versions included text only; 2 included text plus a standard bar graph to represent people who avoided cancer through the 2 prevention plans; and 2 included text plus a culturally tailored bar graph. The 6 versions were 1) text only/relative risk; 2) text only/absolute risk; 3) text/ relative risk plus standard bar graph; 4) text/absolute risk plus standard bar graph; 5) text/ relative risk plus culturally tailored bar graph; and 6) text/absolute risk plus culturally tailored bar graph.

We used the 3 adapted questions to assess risk interpretation for the hypothetical Prevention Plans R and K: 1) Which prevention plan is more effective? (responses = R or K); 2) How many people out of 100 will develop cancer if they participate in Prevention Plan R? (responses $=30,25$, or 20); and 3) How many people out of 100 will develop cancer if they participate in Prevention Plan K? (responses $=30,25$, or 20). Responses to these 3 questions served as the primary outcomes of the analysis. Two additional questions asked respondents how likely they would be to participate in research to test the efficacy of Prevention Plan R and Prevention Plan K (responses = definitely would not, probably would not, not sure, probably would, definitely would). Participants also provided demographic information.

\section{Measures}

Each of the 3 risk interpretation outcomes was coded to indicate whether it was correct; then we calculated the total number of correct outcome questions (range $=0-3$ ) for each participant. The predictors of interest were framing (relative risk vs. absolute risk) and presentation format (text only vs. text plus standard bar graph; text only vs. text plus culturally tailored bar graph). Demographic variables included age, sex, education (high school or less, college or beyond), marital status (married, not married), and binary 
indicators (yes, no) of spending at least $50 \%$ of one's life on a reservation, having a telephone in the home, previous participation in a research study or clinical trial, and personal experience with cancer - defined as self, close friend, or family member being diagnosed with cancer.

\section{Statistical analysis}

We calculated descriptive statistics for students who responded to the 6 survey versions. Chi-square analyses were used to evaluate the success of randomization for the categorical variables, and an analysis of variance was used for age. Because we expected the 3 risk interpretation questions to be strongly correlated within each person, we estimated the intraclass correlation for these questions.

To determine the association between framing, use of bar graphs, and our primary outcome of risk interpretation, we used ordinal logistic models. Ordinal logistic regression was chosen because our primary outcome ranged from 0 to 3 correct answers, and because this method allowed us to adjust for potential confounding factors while providing estimates of odds ratio (OR). We used a multinomial probability distribution and a cumulative logit link function. Our strategy was to fit an initial model with 2 factors: framing ( 2 levels - absolute and relative risk) and presentation format ( 3 levels - text only, text plus standard bar graph, text plus culturally tailored bar graph) and their statistical interaction. In the event of a nonsignificant interaction, the interaction term was removed and the model was refit. To ensure that that our findings were not influenced by potential relationships between demographic variables, college attended, and correct risk interpretation scores, the models were refit to include these variables. Wald's chi-square tests were used to evaluate the significance of the factors, and OR and their 95\% confidence intervals (CI) were used to interpret the strength of the relationships.

Two additional items, which asked how likely students would be to participate in research testing the efficacy of each prevention plan, were examined with respect to their association with framing type, presentation format, and number of correct risk interpretation questions. Responses were dichotomized into "agree" or "not agree" to participate (probably or definitely would vs. definitely would not, probably would not, and not sure). Binary logistic regression analyses were conducted to examine the statistical significance of the associations. All analyses were performed by using SPSS V18.0 (Predictive Analytics Soft Ware, Chicago, IL).

\section{Results}

We collected a total of 576 surveys. Seventy-four were excluded because respondents indicated that they were not AI/AN; 10 lacked answers to the question on heritage; and 3 lacked answers to the questions on risk interpretation. Therefore, our analyses included surveys from 489 students who endorsed being age 18 or older and of AI/AN heritage. Our final sample represented $26 \%$ of all AI/ANs in the combined student bodies of the 3 colleges. Within each college, the percentage of participants ranged from 19\% to $32 \%$, based on online college enrollment statistics [22, 23]. Analyses demonstrated that our sample was representative of the student population of all 3 colleges. The mean age of participants was 28.3 years, while the mean age of students at individual colleges ranged from 27.8 to 34.7 , with a mean age across colleges of 30.7. Our sample was $60.5 \%$ female, compared to $63.5 \%$ across colleges (range $59 \%$ to $69 \%$ ).

Table 1 shows descriptive statistics for demographic and research participation variables, college attended, and personal experience with cancer. Participants were relatively young and predominantly female, and only a small proportion were married. The majority spent at 
least $50 \%$ of their lives on a reservation, had a telephone at home, and had personal experience with cancer. Previous participation in research was rare. The groups that completed each of the 6 versions of the survey were similar on all variables in Table 1, indicating the success of the randomization process.

Table 2 displays the results of the risk interpretation outcome: the average number of correct responses and the percentage of survey participants with $0,1,2$, and 3 correct responses. The intra-class correlation for the risk interpretation questions within person was 0.51 (95\% $\mathrm{CI}=0.42,0.58$ ), indicating moderately strong agreement. The ordinal logistic regression model showed no significant interaction of framing and presentation format (Wald's chisquare $(2)=0.46$ ). We refit the model without the interaction term, which was significant (LR chi-square $=19.55, \mathrm{DF}=3, p<0.0001$ ). In this model, both framing (Wald's chi-square $(1)=4.00, p=0.046$ ) and format (Wald's chi-square $(2)=15.39, p<0.0001$ ) were significant. The OR for framing in terms of absolute risk vs. relative risk was 1.40 (95\% CI $=1.01,1.93)$, indicating that students presented with absolute risks were $40 \%$ more likely than those presented with relative risks to have a correct response. Overall, students who received information in terms of absolute risk had an average score of $1.9(\mathrm{SD}=1.0)$, compared to an average score of $1.7(\mathrm{SD}=1.0)$ for recipients of information in terms of relative risk.

Presentation format was dummy coded in the model, with text only as the reference group. The OR for text plus standard bar graph vs. text only was 2.16 (95\% CI $=1.46,3.19)$, indicating that recipients of text plus standard bar graph were more than twice as likely as recipients of text-only content to interpret risk correctly. Overall, recipients of the standard bar graph averaged 2.0 correct scores $(\mathrm{SD}=1.0)$ compared to $1.6(\mathrm{SD}=1.0)$ for the textonly group. The OR for recipients of culturally tailored bar graphs was $1.72(95 \% \mathrm{CI}=1.14$, 2.60 ), indicating that the culturally tailored group was $72 \%$ more likely to interpret risk correctly than the text-only group. The mean number of correct responses for the culturally tailored group was 1.9 $(\mathrm{SD}=1.0)$. Post hoc Bonferroni testing showed no differences between the standard bar graph and the culturally tailored bar graph. Finally, the variables from Table 1 were added to the model, with the following results: no variable was statistically related to correct risk interpretation scores; both framing and presentation format retained their significance at the same statistical level; and the ORs were essentially unchanged. Because we used 2 different versions of the culturally tailored bar graph, we also compared number of correct responses for the Tribal College A traditional motif vs. the bison motif used in the Tribal Colleges B and C surveys. The difference between the 2 motifs was not statistically significant (results not shown).

Overall, 263 (54\%) of participants endorsed participation in a research study to test the efficacy of Prevention Plan R, and 189 (39\%) endorsed participation in a study to test Plan $\mathrm{K}$. The logistic models showed that framing and presentation format were not related to willingness to participate in research to test either plan. However, number of correct risk interpretation questions was significantly related to willingness to participate: for Plan R, which had a better chance of prevention, higher correct scores were associated with higher likelihood of participation $(\mathrm{OR}=1.63, \mathrm{CI}=1.35,1.96)$. In contrast, for Plan $\mathrm{K}$, which was not as efficacious, higher correct scores were associated with lower likelihood of participation $(\mathrm{OR}=0.82, \mathrm{CI}=0.68,0.98)$. Students who would participate in research to test Plan R had a mean correct score of $2.0(\mathrm{SD}=1.0)$, compared to a mean score of $1.6(\mathrm{SD}=$ 1.0) for those who said they were unsure or would not participate. The reverse pattern was observed for Plan K, such that the mean number of correct answers was higher for students who would not participate $(\mathrm{M}=1.9, \mathrm{SD}=1.0)$ than for students who would participate $(\mathrm{M}=$ $1.7, \mathrm{SD}=1.1$ ). 


\section{Discussion}

In this study, we investigated the influence of 2 kinds of risk framing and 2 types of bar graphs on the understanding of risk information among AI/AN students at tribal colleges. Congruent with earlier studies [2,11,13], including our own with 300 American Indian employees [18], we found that risk information that included a graphic image was better understood than information that included text only. We also compared the influence of a standard bar graph to that of a modified bar graph incorporating a culturally tailored image. Contrary to the hypothesis we developed from focus group discussions, we found that culturally tailored graphs did not enhance comprehension for AI/AN students. This finding was not a total surprise. Although focus groups in one prior study stated a preference for human figures instead of bars in graphs [24], another study found that substitution of asterisks for human figures in an icon array did not result in any difference in study participants' decisions [25]. Notably, an extensive review of graphs used in health risk communication concluded that people's stated preferences for graph designs were not necessarily linked to their quantitative judgments [2]. However, cultural preferences may still be an important component of health communication. A recent study incorporating 13 focus groups made up of American Indian cancer survivors from the Southwest U.S. found that participants preferred educational materials tailored to their belief and culture [26].

We also found that information framed in terms of absolute risk was better understood than information framed in terms of relative risk. This finding was in contrast to findings in both of our earlier studies. Our study of $91 \mathrm{AI} / \mathrm{AN}$ elders found that relative risk was better understood [19], while our study of $300 \mathrm{AI} / \mathrm{AN}$ employees found no statistically significant difference in understanding between relative and absolute risk, although relative risk was associated with slightly higher odds of correct answers [18]. Comparing our results to studies of other populations is more difficult. A review of best practices for risk communication has pointed out that there is a lack of consistency in test formats investigating risk communication [12]. Not surprisingly, research findings from other populations have also been inconsistent $[10,11,27]$. A recent study of over 16,000 people of various races found that both relative (percentage) and absolute (frequency) risk framing yielded similar rates of accurate comprehension in all participants, regardless of race [28]. However, this Internet study added another layer of complexity by requiring participants to perform mathematical operations; nonwhite and less educated respondents had lower scores.

Our findings on the 2 questions about willingness to participate in research studies testing Prevention Plans R and K were somewhat puzzling. As we expected, participants with high risk interpretation scores were more likely to indicate willingness to participate in a research study testing Prevention Plan R, the more effective plan. Yet the same participants showed less willingness to participate in a research study testing Prevention Plan K than did participants with low scores, even though Plan K was still more effective than no plan at all. More than $10 \%$ of participants answered none of the risk interpretation questions correctly, while more than $1 / 3$ answered all 3 questions correctly. Notably, more than $80 \%$ of participants reported that they themselves, a close friend, or a family member had experienced cancer, indicating the importance of understanding cancer risk information in their personal lives. Although cancer rates in American Indians have historically been low, they are steadily increasing, and cancer-related mortality rates in this population are now among the highest of all racial and ethnic groups [29, 30]. American Indians are also disproportionately diagnosed with late-stage cancer, and have a lower 5-year survival rate than other groups [31]. Understanding risk information is crucial to mitigating this health disparity. 
The present study has several limitations. First, because our convenience sample from 3 tribal colleges is not representative of all American Indians, our findings should not be generalized to other groups or to individual tribes. Second, our brief vignette could not capture all factors relevant to comprehending risk information. Third, the standard bar graph and the culturally tailored bar graphs are only 2 examples of potential graphic formats; no definitive conclusions can be drawn about the efficacy of visual images in general with this study population. Fourth, the 2 culturally tailored graphs, while equivalent in height, are not equivalent in width. We chose to place more importance on the wishes of the tribal colleges for cultural representation than on graphic accuracy. This may have affected our results, although our comparative analysis of the 2 cultural motifs did not find a statistically significant difference. Fifth, we did not assess numeracy, nor did we examine the association between risk communication and a clinically significant outcome. Nevertheless, our findings are an important addition to our earlier research in identifying the most effective means of communicating risk information to $\mathrm{AI} / \mathrm{AN}$ people.

In summary, we observed that the use of bar graphs greatly improved risk comprehension over text-only content, but culturally tailored bar graphs were no more effective than standard bar graphs. Alternative measures such as perceived accuracy of the information, preference, or satisfaction may have been more informative for evaluating culturally tailored graphs. Finding the most effective means of conveying risk information to AI/AN communities is crucial to improving health outcomes in this underserved population.

\section{Acknowledgments}

The authors wish to thank all of the tribal college partners who made the study possible: William Freeman, Dan Woods, Cheryl Long Feather, Chastity Clausen, Frank White, Tasheena Big Crane, Angela Blanchard, Rodney First Strike, Susan Hunter, Patrisha Lane, Leslie Morton, and Leah Runs Through. We are also grateful for the enthusiastic participation of tribal college students at our 3 campus sites. Additionally, we thank Steve Charles, Ursula Tsosie, and Johnny Mao for assistance with data collection. This work was funded by grant number UO1 CA114642 from the National Cancer Institute, which supports the Native People for Cancer Control, a Community Networks Program (D. Buchwald, Principal Investigator), and grant number UL1RR025014 from the National Center for Research Resources (N. Disis, Principal Investigator), which supports the Institute for Translational Health Sciences. The contents of this manuscript are solely the responsibility of the authors and do not necessarily represent the official views of the National Cancer Institute or the Institute for Translational Health Sciences.

\section{References}

1. Montori VM, Rothman RL. Weakness in numbers. The challenge of numeracy in health care. J Gen Intern Med. 2005; 20:1071-1072. [PubMed: 16307637]

2. Ancker JS, Senathirajah Y, Kukafka R, Starren JB. Design features of graphs in health risk communication: a systematic review. JAMA. 2006; 13:608-618.

3. Kirsch, IS.; Jungeblut, A.; Jenkins, L.; Kolstad, A. Adult literacy in America: A first look at the findings of the National Adult Literacy Survey. 3. Washington, DC: US Dept of Education, Office of Educational Research and Improvement, National Center for Educational Statistics; 2002.

4. Paasche-Orlow MK, Parker RM, Gazmararian JA, Nielsen-Bohlman LT, Rudd RR. The prevalence of limited health literacy. J Gen Intern Med. 2005; 20:75-184. [PubMed: 15693932]

5. Malenka DJ, Baron JA, Johansen S, Wahrenberger JW, Ross JM. The framing effect of relative and absolute risk. J Gen Intern Med. 1993; 8:543-548. [PubMed: 8271086]

6. Hux JE, Naylor CD. Communicating the benefits of chronic preventive therapy: does the format of efficacy data determine patients' acceptance of treatment? Med Decis Making. 1995; 15:152-157. [PubMed: 7783576]

7. Cranney M, Walley T. Same information, different decisions: the influence of evidence on the management of hypertension in the elderly. Br J Gen Pract. 1996; 46:661-663. [PubMed: 8978112]

8. Misselbrook D, Armstrong D. Patients' responses to risk information about the benefits of treating hypertension. Br J Gen Pract. 2001; 51:276-279. [PubMed: 11458479] 
9. Gigerenzer G. Why does framing influence judgment? J Gen Intern Med. 2003; 18:960-961. [PubMed: 14687283]

10. Sheridan SL, Pignone MP, Lewis CL. A randomized comparison of patients' understanding of number needed to treat and other common risk reduction formats. J Gen Intern Med. 2003; 18:884-892. [PubMed: 14687273]

11. Waters EA, Weinstein ND, Colditz GA, Emmons K. Formats for improving risk communication in medical tradeoff decisions. J Health Commun. 2006; 11:167-182. [PubMed: 16537286]

12. Lipkus IM. Numeric, verbal, and visual formats of conveying health risks: suggested best practices and future recommendations. Med Decis Making. 2007; 27:696-713. [PubMed: 17873259]

13. Feldman-Stewart D, Kocovski N, McConnell BA, Brundage MD, Mackillop WJ. Perception of quantitative information for treatment decisions. Med Decis Making. 2000; 20:228-238. [PubMed: 10772360]

14. Brundage M, Feldman-Stewart D, Leis A, Bezjak A, Degner L, Velji K, Zetes-Zanatta L, Tu D, Ritvo P, Pater J. Communicating quality of life information to cancer patients: a study of six presentation formats. J Clin Oncol. 2005; 23:6949-6956. [PubMed: 16192583]

15. Zikmund-Fisher BJ, Ubel PA, Smith DM, Derry HA, McClure JB, Stark A, Pitsch RK, Fagerlin A. Communicating side effect risks in a tamoxifen prophylaxis decision aid: the debiasing influence of pictographs. Patient Educ Couns. 2008; 73:209-214. [PubMed: 18602242]

16. Mazur DJ, Merz JF. How the manner of presentation of data influences older patients in determining their treatment preferences. J Am Geriatr Soc. 1993; 41:223-228. [PubMed: 8440842]

17. Elting LS, Martin CG, Cantor SB, Rubenstein EB. Influence of data display formats on physician investigators' decisions to stop clinical trials: prospective trial with repeated measures. BMJ. 1999; 318:1527-1531. [PubMed: 10356010]

18. Sprague D, LaVallie D, Wolf F, Jacobsen C, Sayson K, Buchwald D. Influence of graphic format on comprehension of risk information among American Indians. Med Decis Making. 2011; 31:437-443. [PubMed: 21191119]

19. LaVallie DL, Wolf FM, Jacobsen C, Sprague D, Buchwald D. Health numeracy and understanding of risk among older American Indians and Alaska Natives. J Health Commun. 2012; 17:294-302. [PubMed: 22188207]

20. Noe, T.; Manson, SM.; Croy, C.; McGough, H.; Henderson, JA.; Buchwald, DS. In their own voices: American Indian decisions to participate in health research. In: Trimble, J.; Fisher, C., editors. Handbook of Ethical Research with Ethnocultural Populations and Communities. Thousand Oaks, CA: Sage; 2005. p. 93-116.

21. Buchwald D, Mendoza-Jenkins V, Croy C, McGough H, Bezdek M, Spicer P. Attitudes of urban American Indians and Alaska Natives regarding participation in research. J Gen Intern Med. 2006; 21:648-651. [PubMed: 16808751]

22. [Accessed April 16, 2010] Student Body. 2010. Available from: http://www.citytowninfocom/ school-profiles/

23. [Accessed April 16, 2010] Student Enrollment Demographics. 2010. Available from: http:// www.stateuniversity.com/universities/

24. Schapira MM, Nattinger AB, McHorney CA. Frequency or probability? A qualitative study of risk communication formats used in health care. Med Decis Making. 2001; 21:459-467. [PubMed: 11760103]

25. Stone ER, Sieck WR, Bull BE, Yates JF, Parks SC, Rush CJ. Foreground: background salience: explaining the effects of graphical displays on risk avoidance. Organ Behav Hum Decis Process. 2003; 90(1):19-36.

26. Hodge FS, Itty TL, Cadogan MP, Martinez F. "Weaving Balance into Life": development and cultural adaptation of a cancer symptom management toolkit for Southwest American Indians. J Cancer Surviv Dec. 2011; 11 [Epub ahead of print].

27. Schwartz LM, Woloshin S, Black WC, Welch HG. The role of numeracy in understanding the benefit of screening mammography. Ann Intern Med. 1997; 127:966-972. [PubMed: 9412301]

28. Cuite CL, Weinstein ND, Emmons K, Colditz G. A test of numeric formats for communicating risk probabilities. Med Decis Making. 2008; 28:377-384. [PubMed: 18480036] 
29. Clegg LX, Li FP, Hankey BF, Chu K, Edwards BK. Cancer survival among US whites and minorities: a SEER (Surveillance, Epidemiology, and End Results) Program population-based study. Arch Intern Med. 2002; 162:1985-1993. [PubMed: 12230422]

30. Ward E, Jemal A, Cokkinides V, Singh GK, Cardinez C, Ghafoor A, Thun M. Cancer disparities by race/ethnicity and socioeconomic status. CA Cancer J Clin. 2004; 54:78-93. [PubMed: 15061598]

31. Espey DK, Wu XC, Swan J, Wiggins C, Jim MA, Ward E, Wingo PA, Howe HL, Ries LA, Miller BA, Jemal A, Ahmed F, Cobb N, Kaur JS, Edwards BK. Annual report to the nation on the status of cancer, 1975-2004, featuring cancer in American Indians and Alaska Natives. Cancer. 2007; 110:2119-2152. [PubMed: 17939129] 


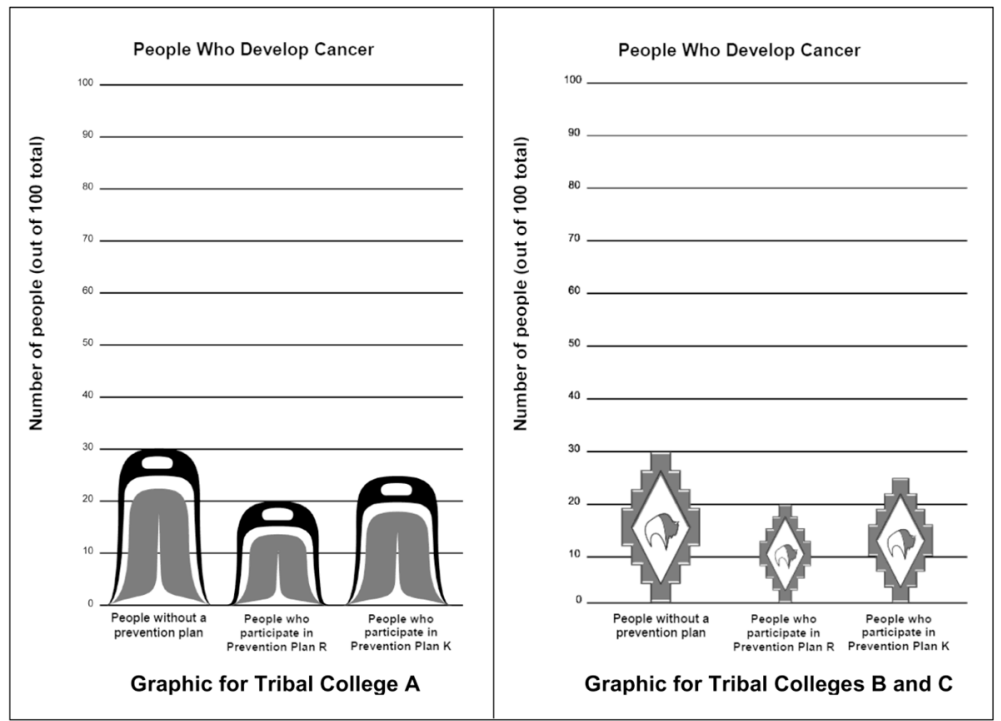

Figure 1.

Culturally tailored bar graphs for Tribal Colleges A, B, and C 


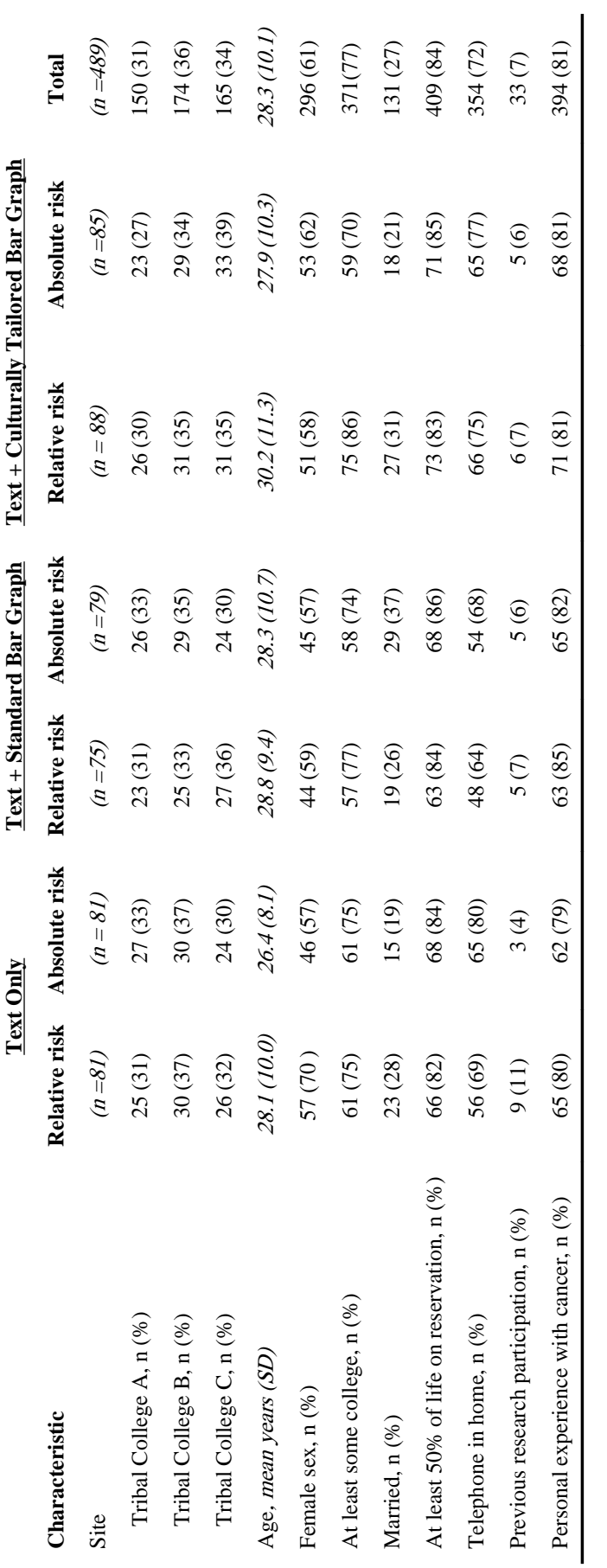


